\title{
Perceptions of women with systemic lupus erythematosus undergoing high-risk prenatal care: A qualitative study
}

\author{
Larissa Rodrigues ${ }^{a}$, Vera Lucia Pereira Alves ${ }^{b}$, Maria Margarida Fialho Sim-Simc ${ }^{c}$, \\ Fernanda Garanhani Surita d,* \\ a School of Medical Science, University of Campinas (UNICAMP), Brazil \\ ${ }^{\mathrm{b}}$ Psychologist Post-Doctoral in Medical Sciences, University of Campinas, Brazil \\ ${ }^{c}$ Department of Nursing University of Évora, Portugal \\ ${ }^{\mathrm{d}}$ Department of Gynecology and Obstetrics, School of Medical Science University of Campinas (UNICAMP), Brazil. R. Alexander Fleming 101, ZIP: 13083-881, \\ Campinas, SP, Brazil
}

\section{A R T I C L E I N F O}

\section{Article history:}

Received 12 December 2019

Revised 23 February 2020

Accepted 30 March 2020

\section{Keywords:}

Pregnancy

Systemic lupus erythematosus

Woman

Mental health

Perinatal

Qualitative research

\begin{abstract}
A B S T R A C T
Background: Systemic lupus erythematosus (SLE) is a multisystem autoimmune disease that often leads to situations of harm to the mother-fetus binomial. Given the potential for complications and morbidities in these pregnant women, it is essential that a multidisciplinary team be involved in pregnancy planning, as well as monitoring the course of the pregnancy and the postpartum period. Owing to the imminent risks of disease worsening along with consequent disabilities, these women may experience psychological and psychosocial impacts conflicting with the psychological demands of pregnancy.

Objective: To understand the meanings attributed to pregnancy by women with SLE.

Design: A qualitative design with face-to-face interview following a semi-structured script of open-ended questions.

Setting: A specialized outpatient clinic where during prenatal care, women with stable disease undergo scheduled appointments.

Participants: The sample was intentionally composed of women visiting a specialized outpatient clinic from July 2017 to July 2018. The participants $(\mathrm{N}=26)$ were interviewed in depth, with no refusal. Thematic analysis according to the 7 steps of qualitative analysis was conducted using NVivo 11.

Findings: Four categories were identified: (1) unplanned pregnancy and nonuse of contraception, (2) feeling healthy despite a doctor's warning of the disease worsening because of pregnancy, (3) joy coupled with fear of the future and pregnancy, and (4) self-perception and straight perception.

Conclusions: The experiences of pregnant women with SLE are permeated by ambiguous feelings. These women feel healthy because they can bear a child despite the chronic disease diagnosis and, at the same time, experience fear and insecurity owing to the imminent possibility of disease-related disabilities and limitations. They especially wish to experience motherhood, and they strive for safety and support.

Implications for practice: Health teams must be structured to welcome and advise these women in planning relationships and pregnancy, as well as choosing the best contraceptive methods and making optimal reproductive decisions. The development of strategies to deal with changes in the perinatal period may be helpful, as these women are willing to take care of themselves.
\end{abstract}

(c) 2020 Elsevier Ltd. All rights reserved.

\footnotetext{
* Corresponding author.

E-mail addresses: rodrigues-larissa@uol.com.br (L. Rodrigues), vera@alves.com (V.L.P. Alves), msimsim@uevora.pt (M.M.F. Sim-Simc), surita@unicamp.br (F.G. Surita).
}

\section{Introduction}

Systemic lupus erythematosus (SLE) is a multisystem autoimmune disease that can affect the skin, joints, kidneys, heart, lungs, and serous membranes, among others, with a prevalence of 40 to 200 cases per 100,000 individuals and a female to male incidence 
ratio of 9:1 (Borella et al., 2014; Pastore et al., 2018; Petri et al., 2012; Fortuna \& Brennan, 2013). Owing to its high prevalence among women of childbearing age (15-45 years), amid pregnant women, the SLE incidence ranges from 1:660 to 1:2.952 and the condition is associated with an increased risk of maternal and fetal complications (Lateef \& Petri, 2017; Shaikh, Jordan, \& D'Cruz, 2017).

Many common conditions, including hypertension, nephropathy, and the presence of autoantibodies, can affect the maternalfetal binomial (Lateef \& Petri, 2017; Shaikh et al., 2017). As results, situations such as preterm birth, cesarean delivery, and preeclampsia have been reported (Harris, Eudy, \& Clowse, 2019) Despite advances in clinical follow-up, the fetal prognosis may still be impaired by common situations such as miscarriage, growth restriction, and prematurity as well as increased maternal mortality rates (Buyon et al., 2015; Pastore et al., 2018)

In such scenarios, challenges exist both related to the management of the disease and pregnancy and in making the distinction between expected physiological changes and manifestations of the disease (Harris et al., 2019).

The ideal time for pregnancy in a woman affected by SLE is when the disease has been in remission for at least six months, when the medication regimen is compatible with pregnancy, and in the absence of disabilities such as heart or pulmonary failure; therefore, it is strongly advised that pregnancy be planned for in advance (Andreoli et al., 2017; Borella et al., 2014; Pastore et al., 2019). Given the potential complications and morbidities that may present in pregnant women with the abovementioned conditions, it is essential to follow the pregnancy and puerperium management plan formulated by the multidisciplinary team in question (Knight \& Nelson-Piercy, 2017; Surita et al., 2007).

In addition, there are major physical, psychic, and emotional transformations inherent in the pregnancy process (Bjelica, Cetkovic, Trninic-Pjevic, \& Mladenovic-Segedi, 2018). Usually, women's expectations revolve around bearing a healthy child and beginning the experience of motherhood.

Throughout pregnancy, psychic movements cause a transformation, priming the woman to welcome her child; thus, her identity as a mother is built on past experiences gained to this point (Falcone et al., 2005). In the context of SLE, with the imminent risk of a worsening condition and the onset of disabilities, women may experience unique psychological and psychosocial impacts (Neri et al., 2004; Tingström et al., 2010), conflicting with the psychological demands of pregnancy.

In such a situation, how women perceive the disparity between the promise of a new life and the threat of more severe SLE? In an attempt to answer this question, this study aims to understand the meanings attributed to pregnancy by pregnant women with SLE during prenatal care.

\section{Methods}

\section{Study design}

The study design used was based on the qualitative method (Turato, 2011; Fontanella, Campos \& Turato, 2006) which is constructed via three pillars: (1) a clinical attitude that values listening and contact between the health care professional and patient; (2) an existentialist attitude that values the problems experienced by a participant; (3) and a psychoanalytic attitude that accepts the existence of the unconscious psychic instance that lies between the lines of the discourses and the behavior of the participants.

\section{Research setting}

The study setting was a single specialized outpatient clinic where, during prenatal care, women with stable disease undergo scheduled appointments. On a weekly basis, about 40 pregnant women diagnosed with high blood pressure, sickle cell anemia, cancer, and autoimmune diseases are treated at this clinic, and the average annual number of pregnant women patients treated with SLE is 25 .

Sampling

The selection of participants was intentional. All women had in common the experience of pregnancy and SLE diagnosis and were under care at the clinic in question. All participants were in the third trimester of pregnancy, near 30 weeks of gestation. Finally, all women visiting the clinic from July 2017 to July 2018 were invited to participate and all those who were invited agreed to be part of the present study.

\section{Approaching the participants}

The first author (L. R.) established the field setting between November 2016 and July 2017. Study data were collected via 1 interview with each participant. Prior to each interview, a rapport was established by creating an atmosphere of empathy, trust, and responsiveness. Participants were provided with an explanation of the research topic, study aims, and rights of the parties involved, with sociodemographic data were collected thereafter. Written permission to use a tape recorder was sought.

Subsequently, the first author (L. R.) conducted the interviews using a semi-structured script with six open-ended questions designed to explore the following themes: feelings about being an SLE carrier, experience with carrying this disease while being pregnant, pregnancy monitoring, sexual behaviors after finding out about the illness and pregnancy, and daily life.

The question script was created to guide the interviewer during the data collection process but was flexible to account for the interviewee's speech flow, with no need to ask the questions in a certain sequence. Behavioral and intervening aspects were recorded in a field diary.

The interviews took place on the same day that the patients underwent prenatal consultations and were held in a private room previously prepared to receive each participant after acceptance. This room had two chairs facing each other (interviewee and interviewer) without tables or clipboards or any materials that would distance the two people or indicate any power.

\section{Data analysis and validation}

Following data collection, seven steps of content analysis (FariaSchützer, et al., 2018) were performed. These were:

1 Text editing for transcription of the recorded interviews and field diary notes organized by the first author (L.R.); the interviews were transcribed verbatim by the first author (L.R.) and later had grammar corrected grammar to facilitate the reader's understanding

2 Listening to and re-reading of the material by two independent authors (L. R. and F. G. S.)

3 Documenting impressions of the re-reading by registering emerging and meaningful themes in the right margin of the transcribed text

4 Organizing all generated content under categories and subcategories to identify patterns of meaningful units and main features of the text, carried out while taking into account the relevance implicit in each interview as well as the frequency (Bardin, 2011; Berelson, 1984) of the appearance of a theme

5 Debating disagreements that arose between the two authors ( $\mathrm{L}$. R. and F. G. S.) with the other authors until a consensus was 
reached (V.L.P.A.), followed by presentations in research groups and congresses to attain validation of the material

6 Establishment of categories based on the authors' interpretation and discussions

7 Data validation by peers (all authors) and members of the research group

Here, NVivo 11 (QSR International, Melbourne, Australia) was used for material organization beginning with the first step. The COREQ checklist (Tong et al., 2007) was used to promote good qualitative rigor of the study.

\section{Ethical aspects}

This study complies with National Health Council Resolution No. 466 (Brazil, 2012) on health research with human beings. It was authorized by the local ethics committee under no. 68143817.0.0000.5404. All content gathered from the interviews was treated confidentially. The first author (L.R.) read and explained the free and informed consent form to the participants, who signed the document after the necessary clarifications were made. One copy of the document remained with the researcher and the other copy was given to the participant.

\section{Results}

Our sample included 26 participants interviewed in depth, with the per-interview average (standard deviation) length of time being 29.14 (14.22) minutes. The average age of the study population was 28.80 (4.30) years and the average time since SLE diagnosis was 9.5 (6.50) years. All participants reported experiencing previous disease activity but stability during the current pregnancy. Seven patients had previously experienced miscarriages, 14 had other living children, and five were in their first pregnancy. Most reported having a partner and some religiosity, and half of them were white. The participants' characteristics are described in Table 1.

Table 1. Participants' Characteristics
During data analysis, four categories were identified as follows: (1) unplanned pregnancy and nonuse of contraception, (2) feeling healthy despite a doctor's warning of the disease worsening because of pregnancy, (3) joy coupled with fear of the future and pregnancy, and (4) self-perception and straight perception.

The following categories reflect the meta-aggregation of the collected data. The process of elaborating these structures is illustrated in Figure 1.

\section{Unplanned pregnancy and nonuse of contraception}

This theme represents the ambiguous domain between planning failure and the veiled desire to get pregnant. Participants seemed to deny the obstetric risk associated with their condition or the possibility of conceiving. Pregnancy appeared to be a challenge, with success seeming to empower the participants and give them a sense of having overcome the disability caused by the disease. Many of these disabilities were imagined.

E23. It was a surprise. I did not use contraception because, despite being sexually active, I never got pregnant and, thus, believed it wouldn't happen. I thought the medications I used to take for lupus had destroyed my womb and that I wouldn't ever get pregnant. That was my gut feeling. However, I got pregnant.

\section{Reasons for continuing with this pregnancy}

Association between the partner's desire to have a child appears as in the women's speech, they face the risks of pregnancy in the presence of the disease to satisfy the partner.

E25. While the reason for this pregnancy was a desire to strengthen our bond, I have decided [that] this is the last time. I won't put myself at risk again.

The impossibility of using effective contraceptive methods available due to the disease is present in the speech of women.

E24. I was not planning on getting pregnant, especially because I was unemployed. It was an accident. We used only condoms because of the hormone issues associated with lupus.

Table 1

Characteristics of women with lupus in prenatal care

\begin{tabular}{|c|c|c|c|c|c|c|c|c|c|c|c|}
\hline Interview & $\begin{array}{l}\text { Age } \\
\text { (years) }\end{array}$ & $\begin{array}{l}\text { Skin } \\
\text { color }\end{array}$ & Religious & Partner & $\begin{array}{l}\text { Paid } \\
\text { work }\end{array}$ & Schooling & $\begin{array}{l}\text { Number of } \\
\text { pregnancies }\end{array}$ & $\begin{array}{l}\text { Gestational } \\
\text { losses }\end{array}$ & $\begin{array}{l}\text { Years of } \\
\text { diagnosis }\end{array}$ & $\begin{array}{l}\text { Planned } \\
\text { pregnancy }\end{array}$ & $\begin{array}{l}\text { Use of } \\
\mathrm{CM}^{*}\end{array}$ \\
\hline 1 & 29 & Mix & Evangelical & Yes & Yes & $\mathrm{HS}^{* *}$ & 1 & 0 & 9 & No & No \\
\hline 2 & 25 & Black & Evangelical & Yes & Yes & HS & 1 & 0 & 2 & No & No \\
\hline 3 & 27 & White & Catholic & Yes & Yes & HS & 1 & 0 & 4 & No & No \\
\hline 4 & 28 & Mix & Catholic & Yes & Yes & HS & 3 & 0 & 3 & No & No \\
\hline 5 & 24 & White & Catholic & No & No & HS & 1 & 0 & 3 & No & No \\
\hline 6 & 23 & White & Catholic & Yes & Yes & $\mathrm{TE}^{* * * *}$ & 1 & 0 & 2 & No & No \\
\hline 7 & 23 & Mix & Believes in God & Yes & No & $\mathrm{ES}^{\#}$ & 1 & 0 & 5 & No & No \\
\hline 8 & 22 & White & Catholic & No & Yes & $\mathrm{UE}^{\# \#}$ & 1 & 0 & 12 & No & No \\
\hline 9 & 30 & Mix & Not religious & Yes & Yes & HS & 1 & 0 & 9 & No & No \\
\hline 10 & 28 & White & Believes in God & No & No & ES & 3 & 0 & 23 & No & Yes \\
\hline 11 & 33 & White & Catholic & Yes & Yes & HS & 3 & 1 & 5 & Yes & Yes \\
\hline 12 & 32 & Mix & Evangelical & No & Yes & HS & 4 & 2 & 3 & No & No \\
\hline 13 & 34 & White & Believes in God & Yes & Yes & UE & 5 & 0 & 6 & No & No \\
\hline 14 & 28 & Mix & Evangelical & Yes & Yes & HS & 2 & 0 & 18 & No & Yes \\
\hline 15 & 34 & White & Evangelical & Yes & Yes & HS & 2 & 0 & 7 & Yes & No \\
\hline 16 & 29 & White & Catholic & Yes & Yes & HS & 2 & 0 & 4 & No & Yes \\
\hline 17 & 28 & Mix & Catholic & Yes & Yes & HS & 3 & 0 & 17 & No & No \\
\hline 18 & 33 & Mix & Evangelical & Yes & Yes & HS & 3 & 1 & 6 & No & Yes \\
\hline 19 & 19 & White & Christian & Yes & Yes & HS & 1 & 0 & 12 & No & No \\
\hline 20 & 26 & White & Catholic & Yes & Yes & HS & 3 & 2 & 13 & Yes & No \\
\hline 21 & 30 & Black & Catholic & Yes & Yes & UE & 3 & 0 & 13 & No & No \\
\hline 22 & 33 & White & Catholic & Yes & No & UE & 1 & 0 & 13 & Yes & No \\
\hline 23 & 31 & Black & Non confessional & Yes & No & HS & 3 & 0 & 7 & No & No \\
\hline 24 & 30 & White & Non confessional & Yes & No & UE & 2 & 1 & 23 & Yes & No \\
\hline 25 & 35 & White & Sei-Sho-No-Ie & Yes & No & HS & 2 & 1 & 21 & No & Yes \\
\hline 26 & 35 & White & Evangelical & Yes & Yes & HS & 4 & 2 & 7 & No & No \\
\hline
\end{tabular}

${ }^{*} \mathrm{CM}$ - Contraception Methods, ${ }^{* *} \mathrm{HS}$ - High School, ${ }^{* * *} \mathrm{TE}-$ Technical Education, ${ }^{\#}$ ES - Elementary School, ${ }^{\# \#}$ UE - University Education 

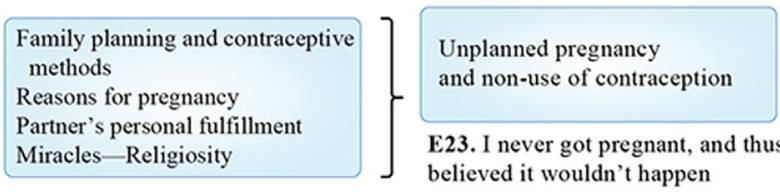

\begin{tabular}{|l|} 
Doctor's opinion \\
Self-image \\
Self-perception \\
Willingness to engage in self-care \\
Treatment control
\end{tabular}

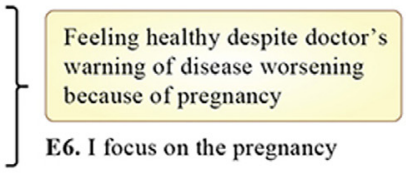

Fear of pregnancy complications
Afraid of not being able to take
care of the child
Pregnancy losses
Neonatal losses
Death
Job loss
Loss of autonomy
Loss of decision-making power

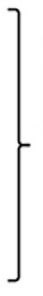

$$
\begin{aligned}
& \text { Joy coupled with fear of } \\
& \text { the future and pregnancy }
\end{aligned}
$$

E21. Oh my God, I don't want to die now!" I have to look after my children, I want to take care of them until they grow up

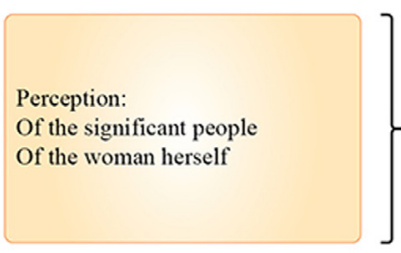

they said: "You can't get pregnant

because you and your baby may be

in danger". I was very sad because

every woman wants to be a mother.
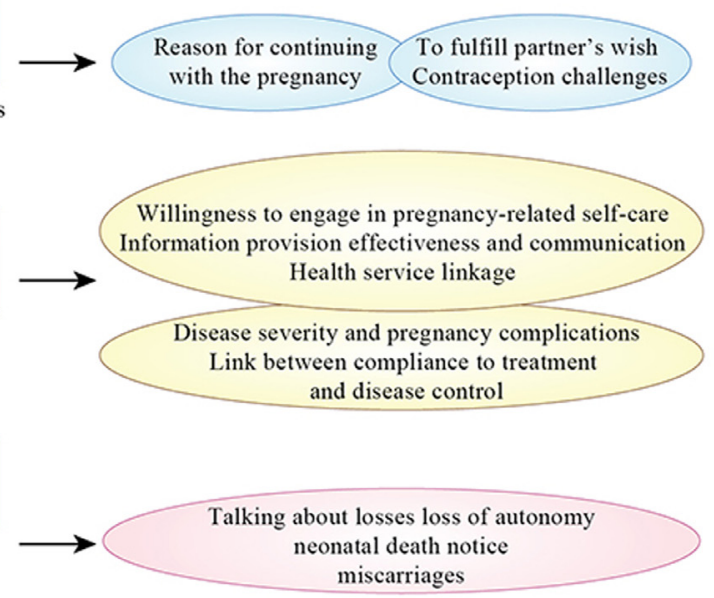
eonatal death notice

Significant people

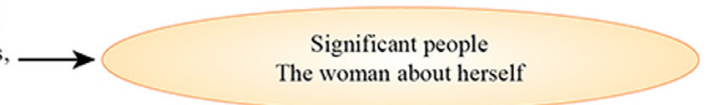

Figure 1. Comprehending interview reports and the category construction process.

There were also reports of women who underwent proper pregnancy planning.

E15. [It]s been nine years [of waiting] for this to happen [pregnancy]. Then, the day of my appointment arrived and I said to the doctor, "look, I can't have a child" and so on. On that occasion, she said: "It's a great time for you to have a child." So when she said that...Wow! Because, every time I asked [previously], [the answer was] "No! No! No." I would leave sad [and] devastated. And, on that day, she said yes. So, I was very happy and thought "wow! I am fine." And I was at ease.

\section{Feeling healthy despite doctor's warning of disease worsen- ing because of pregnancy}

This category reflects the interplay between having a disease and the choice to feel sick or healthy. In this specific situation, it seems that the idea of "bringing forth life" is a kind of cure because it leaves no space for disease in the pregnancy experience.

E6. I take the medication but I tend to forget that I have lupus. Sometimes there is a reddening of the skin and I have to put on some sunscreen, a habit I didn't previously have. These things serve as a reminder [of the disease] but they become inconsequential as I focus on the pregnancy.

\section{Feeling sick because of medication use}

The participants expressed displeasure with the side effects of their medication. Since the disease would eventually go into remission, they attributed all discomfort and symptoms to the prescribed medications. That connects then with a professional relationship.

E20. I stopped taking hydroxychloroquine on my own. I even told the doctor that I wasn't going to take it anymore because it was causing major hair loss and because I felt it was bad for me... I feel so well that taking medication is just an obligation.
Doctors know what we have to do. But, if it were up to me, I wouldn't take it because I feel fine. My body is fine, you know?

Willingness to pursue self-care related to SLE in pregnancy

The participants wished to engage in self-care and comply with the treatment proposals for the benefit of the pregnancy and the baby.

E07. Earlier, I didn't care about going to the doctor but [this is] not [true] nowadays (with the pregnancy). Now, I don't think only about myself; I think of the baby [and] I think about the life to come. Because I never imagined being pregnant, I didn't think I had what it takes. But, I think it happened for the better...

Information provision and the effectiveness of communication with health care providers

The relationship of the woman with the health professional will mark the woman's life. This mark can be positive or negative depending upon the quality of communication. This subcategory highlights the importance of assertive communication between health professionals and women with SLE.

E19. We are not kept informed of all relevant matters. Even when I started treatment with a high-risk doctor, I wasn't told about the risks of pregnancy. Another professional I visited gave me a huge scare by saying that the risk was very great and that, in most cases, either the child or the mother dies. I think [the resulting] anxiety worsened my condition and, at present, the lupus bothers me a lot. 


\section{Disease severity and pregnancy complications}

This subcategory reflects the brush with reality; the possibility of complications and negative outcomes for oneself and the fetus. It reflects the very real presence of SLE.

E26. Sometimes we have to insist that they pass information on to us; otherwise, they don't tell us, and we end up uninformed... Sometimes we feel something, go to a medical appointment, and they say: "how are you?" But, when I don't even know what the disease entails, how am I going to talk about it?

Link between compliance with treatment and disease control

This subcategory reflects women's perception of the need for SLE monitoring and treatment.

E24. I do not think I need it [all the treatment prescribed during pregnancy].

E26. I told the doctor that I intended to get pregnant. I was young but I had wanted to have a child since before I knew I had lupus. He said, "look, you can get pregnant, but it will be a high-risk pregnancy."

\section{Joy coupled with fear of the future and pregnancy}

This category reflects a fear of death and of the possible disabilities associated with SLE. This is further correlated with the possibility of not being able to take care of the child. Therefore, the interviewed women reported lifestyle changes related to the desire to be in good health so as to live with the baby and experience motherhood.

E21 I feel fearful because this disease has no cure, only treatment, so sometimes one gets psychologically distressed. Overwhelmed by sadness, anguish, and fear, I say, "oh my God, I don't want to die now!" I have to look after my children, I want to take care of them until they grow up.

E17. How am I going to take care of a baby if I can't even take care of myself properly? It has to be bathed, taken care of... A baby needs all sorts of care, so I ask myself "how are you going to do this? On days you are in pain, how are you going to handle it? On days that you are sick, with whom will you leave the baby [with] so you can go to the hospital?"

The participants reported that they do not share their concerns for fear of increasing everyone's suffering and try to appear strong.

E18. Regarding family members: spare them. When you expose your suffering, they suffer harder. My mother started to cry. I said, "don't cry, because you have to be stronger than me."

\section{Talking about losses}

Women talked about the loss of autonomy during pregnancy with lupus.

E18. I needed to be hospitalized and the doctor said, "then, do you accept the hospitalization?" I [responded] "there is no way of not accepting it, doctor." Imagine if I don't accept it and I have thrombosis at home because of the lack of treatment and I lose my baby.

There was the consideration of gestational and neonatal losses in the participants' statements.

E26. When I found out [about my pregnancy], I was happy and worried at the same time. The worry came from the fact that I was taking a lot of medication for lupus, which I was afraid would affect the fetus. My husband and my son, too; we all wanted that child. So, we wanted it. When I found out it was there, that lifeless child, I couldn't accept it. That loss was hard for me. I cried a lot.

E12. I hate answering phone calls at night. The ringing of the phone at that time instills in me a horrible fear of receiving news of death.

\section{Self-perception and straight perception}

This category suggests the women's self-image: sick and pregnant. It also reflects how the participants imagined they were perceived by significant people such as family members, friends, and even strangers.

The women reflected on themselves that their lives and desires evolve over time but everything remains shaped by lupus because the disease does not pass.

E15. I started treatment when I was single, then I got married. And then, at some point, you want to have a child, right? And, when I questioned the doctors, they said, "you can't get pregnant because you and your baby may be in danger." I was very sad because every woman wants to be a mother.

Among significant people, the woman perceives a constant concern exists about her health and even a strangeness that a woman sick with lupus is pregnant.

E17. Everybody in my family was happy [about pregnancy] but they had concerns about my health. Once you speak about lupus and pregnancy, everyone gets scared.

E22. People see the limitation. I don't. It can even be funny. Everyone worries a lot. Many people told me they were worried, that they even thought I could not get pregnant. Sometimes it's because they don't know much about the disease.

\section{Discussion}

Our results allow us to gain an understanding of the perceptions of pregnant women with SLE. Ambiguous aspects were clarified through organization into themes such as (1) unplanned pregnancy and nonuse of contraception, (2) feeling healthy despite a doctor's warning of the disease worsening because of pregnancy, (3) joy coupled with fear of the future and pregnancy, and (4) self-perception and straight perception.

The average duration since diagnosis with this chronic disease was seven years. Considering the imminent possibility of the disease worsening and perinatal complications, pregnancy planning and the very desire to get pregnant are topics that health care professionals should discuss with women diagnosed with SLE. This would engender the possibility of choosing an effective contraceptive method $(\mathrm{CM})$ and the best time for pregnancy.

The World Health Organization (WHO) publishes and updates the best contraception practices for medical conditions, as well as large-scale family planning models (national level) (WHO, 2018). Moreover, a study on contraception best practices (Fox et al., 2018) suggests that women prefer to use the services of qualified counselors who empower them to make their own decisions about CMs and who prioritize their autonomy and respect their preferences.

The majority of women in this sample reported either no contraceptive use or the misuse of CM. Thus, in the context of women with SLE, selecting adequate contraception may be a challenge for health care teams.

Another issue that warrants attention in this population is that these women do not want to think about their disease; they would rather focus on the pregnancy. This reveals a great motivation because they feel healthy and attribute it to the fact that they are 
pregnant. However, this is associated with an increased risk of nonadherence to prescribed medications. Psychologically, this may be an act of denial of the disease and its consequences can include inefficacy or the complete discontinuation of treatment.

Another rationale for discontinuing medication is the associated feelings of sickness. These findings are consistent with the literature (Haag et al., 2018); further, patients' understanding of their treatment has a profound effect on their perceptions, compliance, and withdrawal. Sometimes, women seem to believe that the impact of SLE is not severe enough to justify the use of such strong medications, possibly because they are in remission when the disease is not actively manifested.

However, participants also displayed an increased willingness to pursue self-care and compliance with SLE treatment during pregnancy, reporting commitment to changing their habits to offer the pregnancy and the baby the best possible chance of flourishing. Therefore, the pregnancy may represent a great opportunity for discussion and intervention by health professionals. This complements the literature on prenatal health interventions that emphasizes this as an opportunity for good short-term outcomes (Solhi et al., 2019; Miller, 2016; Shorey \& Ng, 2019; Rasouli et al., 2019).

The side effects of medications used for controlling SLE can also lead to changes in self-concept and body image, which may cause a woman not to identify with herself. This engenders psychological and social impacts activated by the visibility of the disease. Participants reported experiencing social isolation, sadness, and hopelessness because of their disease-related self-image. In this sense, our findings corroborate prior literature (Rutter \& Kiemle, 2015; Jolly et al., 2012) correlating self-image disorders with treatment manifestations and disease symptoms. The available literature largely mentions also about women's experiences during the perinatal period regarding the complexity of body image (Fuller-Tyszkiewicz, Skouteris, Watson, \& Hill, 2013; B. Watson, Fuller-Tyszkiewicz, Broadbent, \& Skouteris, 2015). Thus, we emphasize the difficulty in attributing the perceptions related to selfconcept and body image solely to the pregnancy or to the lupus. As such, we limit ourselves only to highlighting the observation in our findings.

Disease activity may lead women with SLE to experience temporary or permanent disabilities, and participants expressed fear in this regard. Even if they do not actually experience a disability, there is a constant feeling of imminent risk, leading to anxiety. In this sense, it seems that the guarantee of a support system that helps the mother to care for both herself and the newborn would contribute to increasing her sense of security.

The participants frequently mentioned gestational and neonatal losses; past losses instilled anxiety and fear about the possibility of future losses. Therefore, it is essential that the services offered to pregnant women with SLE include the discussion of ways to accept their losses while also supporting them in their grief. This reflection corroborates the literature that observes the need for adequate support in situations of loss (Watson et al., 2019). Especially in the event of a new pregnancy, support offered using appropriate strategies can reduce anxiety and improve maternal attachment to the new baby (Lamb, 2002).

The women of this study reported that, at times, their relationships with other people were influenced by ignorance, prejudice, and discrimination. SLE causes various difficulties in daily life, especially in the context of how people view the associated changes in the patient's physical appearance. The women related this to the manifestation of the disease as well as to the consequences and adverse effects of treatment, and a similar situation can be seen in cases of other discriminatory or stigmatizing factors (Mascayano et al., 2015; Faria-Schützer, et al., 2018).
This perception of prejudice and discrimination may be another factor related to the development of mental health problems. Our participants reported experiencing a realistic level of fear regarding what the disease might cause or bring on in the future. The existence of SLE, which has both psychological and psychosocial dimensions, demands a commitment to ensuring mental health and calls for cooperation among health care professionals to meet the needs of these women (Nowicka-Sauer et al., 2018).

The women interviewed also revealed a desire to feel active and unrestrained. This indicates that working can promote a sense of wellness. In this respect, our study is in agreement with other literature on work as a health intervention (Booth et al., 2018; Gordon et al., 2013).

Finally, participants referred to the active stage of disease as a moment of disturbance. However, the literature highlights the role of stressful social factors contributing to the progression of SLE and correlates lower family income with greater damage caused by the disease (Chae et al., 2015).

Given the above, we can infer some particularities of women with lupus while in prenatal care. Most of our participants did not plan on becoming pregnant but many of them demonstrated a veiled desire for pregnancy, finding nonphysiological justifications for the occurrence of their pregnancy. Their perceptions prompt us to consider the health care gaps that contribute to the occurrence of unplanned pregnancies.

\section{Limitations and strengths}

This research contributes to the existing pool of literature on SLE, detailing how women perceive their disease in the context of pregnancy. Based on the results, when women with SLE visit the doctor, they can and should be armed with information that goes beyond epidemiological data, enabling better communication. In addition, this study highlights the need for broad mindsets that go beyond simply the clinical context.

These data emphasize the importance of empowering pregnant and sick women without ignoring their need for constant and solid support. However, the study has some limitations as well. As the participants belonged to a specific region of a country with great diversity, attempts to generalize the results must be conducted with caution. Further research involving other groups of women is required with the intention of showing differences and similarities between groups with different characteristics.

\section{Conclusions}

Women with lupus who became pregnant and were treated at a high-risk prenatal clinic had experiences permeated by ambiguous feelings. These women felt healthy because they found that they could have a child despite being diagnosed with a chronic disease; at the same time, they experienced fear and insecurity because of the imminent possibility of disease-related disabilities and limitations. Further, they had a strong desire to experience motherhood but concerns regarding safety and support, owing to the possibility of limitations related to the disease interfering in adverse ways.

The understanding of these women's experiences afforded by this study can lead to and support improvements in clinical management and approaches. Thus, this study seeks to offer health professionals relevant information about the greater scope of service required when caring for pregnant women with SLE. Health teams can be structured to accommodate and advise these women when planning for relationships and pregnancy and how to choose the best $\mathrm{CMs}$ and make optimal reproductive decisions. It can also aid in the development of strategies to facilitate behavioral changes in the perinatal period since these women are willing to take care of themselves. Thus, this period can be used to prepare 
women for managing their disease and their reproductive lives more diligently.

\section{Ethical Approval}

This study complies with National Health Council Resolution No. 466 (BRAZIL. Ministry of Health. National Health Council, 2012) on health research with human beings. It was authorized by the local ethics committee under CAAE no. 68143817.0.0000.5404.

\section{Funding Sources}

This work supported by Coordination of Improvement of Higher Education Personnel - Brazil (CAPES) no. 88881.188510/2018-01.

\section{Declaration of Competing Interest}

None declared

\section{Acknowledgements}

Providing support: Coordination of Improvement of Higher Education Personnel CAPES/Brazil.

Providing validation of search: SARHAS'Lab/UNICAMP, UEVORA. Providing language help: Elsevier and Cambridge proofreading Providing Illustration help: Elsevier

\section{References}

Andreoli, L., Bertsias, G.K., Agmon-Levin, N., Brown, S., Cervera, R., CostedoatChalumeau, N., Tincani, ..., 2017. EULAR recommendations for women's health and the management of family planning, assisted reproduction, pregnancy and menopause in patients with systemic lupus erythematosus and/or antiphospholipid syndrome. Ann Rheum Dis 76 (3), 476-485. doi:10.1136/ annrheumdis-2016-209770.

Bardin, L. 2011. Content Analysis. Edições, 70 São Paulo.

Berelson, B., 1984. Content analysis in communication research. Hafner, New York.

Bjelica, A., Cetkovic, N., Trninic-Pjevic, A., Mladenovic-Segedi, L., 2018. The phenomenon of pregnancy - a psychological view. Ginekol Pol 89 (2), 102-106. doi:10.5603/GP.a2018.0017.

Booth, S., Price, E., Walker, E., 2018. Fluctuation, invisibility, fatigue - the barriers to maintaining employment with systemic lupus erythematosus: results of an online survey. Lupus 27 (14), 2284-2291. doi:10.1177/0961203318808593.

Borella, E, Lojacono, A, Gatto, M, et al., 2014. Predictors ofMaternal and fetal complications in SLE patients: a prospective study. Immunol Res 170. doi:10.1007/ s12026-014-8572-6.

BRAZIL, December 12, 2012. Ministry of Health. National Health Council. Resolution no. 466. Approves regulated guidelines and standards for research involving human beings. Diário Oficial da União, Brasília.

Buyon, J.P., Kim, M.Y., Guerra, M.M., Laskin, C.A., Petri, M., Lockshin, M.D., ... Salmon, J.E., 2015. Predictors of Pregnancy Outcome in a Prospective, Multiethnic Cohort of Lupus Patients. Ann Intern Med 163 (3), 153-163. doi:10.7326 m14-2235.

Chae, D.H., Drenkard, C.M., Lewis, T.T., Lim, S.S., 2015. Discrimination and Cumulative Disease Damage Among African American Women With Systemic Lupus Erythematosus. Am J Public Health 105 (10), 2099-2107. doi:10.2105/ajph.2015. 302727.

Faria-Schützer, D.B., Surita, F.G., Rodrigues, L., Turato, E.R., et al., 2018. Eating behaviors in postpartum: a qualitative study of women with obesity. Nutrients doi:10.3390/nu10070885.

Fontanella, B.J.B., Campos, C.J.G., Turato, E.R., 2006. Data collection in clinicalqualitative research: Use of non-directed interviews of open questions by health professionals. Rev. Lat. Am. Enferm. 14, 812-820. doi:10.1590/ S0104-11692006000500025.

Fortuna, G., Brennan, M.T., 2013. Systemic lupus erythematosus: epidemiology, pathophysiology, manifestations, and management. Dent Clin North Am 57 (4) 631-655. doi:10.1016/j.cden.2013.06.003.

Fox, Edith, Reyna, Arlene, Malcolm, Nikita M., Rosmarin, Rachel B., Zapata, Lauren B., Frederiksen, Brittni N., ... Dehlendorf, Christine, 2018. Client Preferences for Contraceptive Counseling: A Systematic Review. American Journal of Preventive Medicine 55 (5), 691-702. doi:10.1016/j.amepre.2018.06.006.

Fuller-Tyszkiewicz, M., Skouteris, H., Watson, B.E., Hill, B., 2013. Body dissatisfaction during pregnancy: a systematic review of cross-sectional and prospective correlates. J Health Psychol 18 (11), 1411-1421. doi:10.1177/1359105312462437.

Gordon, C., Isenberg, D., Lerstrom, K., Norton, Y., Nikai, E., Pushparajah, D.S., Schneider, M., 2013. The substantial burden of systemic lupus erythematosus on the productivity and careers of patients: a European patient-driven online survey. Rheumatology (Oxford) 52 (12), 2292-2301. doi:10.1093/rheumatology/ket300.
Haag, Hans, Liang, Tim, Avina-Zubieta, J, Antonio, De Vera, Mary A, 2018. How do patients with systemic autoimmune rheumatic disease perceive the use of their medications: a systematic review and thematic synthesis of qualitative research. BMC Rheumatology 2 (1), 9. doi:10.1186/s41927-018-0017-8.

Harris, N., Eudy, A., Clowse, M., 2019. Patient-Reported Disease Activity and Adverse Pregnancy Outcomes in Systemic Lupus Erythematosus and Rheumatoid Arthritis. Arthritis Care Res (Hoboken) 71 (3), 390-397. doi:10.1002/acr.23621.

Jolly, M., Pickard, A.S., Sequeira, W., Wallace, D.J., Solem, C.T., Mikolaitis, R.A., . ., Cash, T.F., 2012. A brief assessment tool for body image in systemic lupus erythematosus. Body Image 9 (2), 279-284. doi:10.1016/j.bodyim.2011.11.001.

Knight, C.L., Nelson-Piercy, C., 2017. Management of systemic lupus erythematosus during pregnancy: challenges and solutions. Open Access Rheumatol 9, 37-53. doi:10.2147/oarrr.s87828.

Lamb, E.H., 2002. The impact of previous perinatal loss on subsequent pregnancy and parenting. J Perinat Educ 11 (2), 33-40. doi:10.1624/105812402X88696.

Lateef, A., Petri, M., 2017. Systemic Lupus Erythematosus and Pregnancy. Rheum Dis Clin North Am, 43 (2), 215-226. doi:10.1016/j.rdc.2016.12.009.

Mascayano, F., Toso-Salman, J., Ruiz, B., Warman, K., Jofre Escalona, A., Alvarado Munoz, R., . . ., Yang, L.H., 2015. What matters most': stigma towards severe mental disorders in Chile, a theory-driven, qualitative approach. Rev Fac Cien Med Univ Nac Cordoba 72 (4), 250-260.

Miller, T.A., 2016. Health literacy and adherence to medical treatment in chronic and acute illness: A meta-analysis. Patient Educ Couns 99 (7), 1079-1086. doi:10. 1016/j.pec.2016.01.020.

Neri, F., Chimini, L., Filippini, E., Motta, M., Faden, D., Tincani, A., 2004. Pregnancy in patients with rheumatic diseases: psychological implication of a chronic disease and neuropsychological evaluation of the children. Lupus 13 (9), 666-668. doi:10.1191/0961203303lu2003oa.

Nowicka-Sauer, K., Hajduk, A., Kujawska-Danecka, H., Banaszkiewicz, D., Smolenska, Z., Czuszynska, Z., Siebert, J., 2018. Illness perception is significantly determined by depression and anxiety in systemic lupus erythematosus. Lupus 27 (3), 454-460. doi:10.1177/0961203317751858.

Pastore, D.E.A., Costa, M.L., Surita, F.G., 2019. Systemic lupus erythematosus and pregnancy: the challenge of improving antenatal care and outcomes. Lupus, 961203319877247 doi:10.1177/0961203319877247, [Epub ahead of print].

Pastore, D.E.A., Costa, M.L., Parpinelli, M.A., Surita, F.G., 2018. A Critical Review on Obstetric Follow-up of Women Affected by Systemic Lupus Erythematosus. Rev Bras Ginecol Obstet 40 (4), 209-224. doi:10.1055/s-0038-1625951.

Petri, M., Orbai, A.M., Alarcon, G.S., Gordon, C., Merrill, J.T., Fortin, P.R., ... Magder, L.S., 2012. Derivation and validation of the Systemic Lupus International Collaborating Clinics classification criteria for systemic lupus erythematosus. Arthritis Rheum 64 (8), 2677-2686. doi:10.1002/art.34473.

Rasouli, M., Pourheidari, M., Hamzeh Gardesh, Z., 2019. Effect of Self-care Before and During Pregnancy to Prevention and Control Preeclampsia in High-risk Women. Int J Prev Med 10 (21). doi:10.4103/ijpvm.IJPVM 300 17.

Rutter, S.J., Kiemle, G., 2015. Exploring the social and interpersonal experiences of South Asian women with a diagnosis of Systemic Lupus Erythematosus. Psychology \& health 30 (3), 318-335. doi:10.1080/08870446.2014.972397.

Shaikh, M.F., Jordan, N., D'Cruz, D.P., 2017. Systemic lupus erythematosus. Clin Med (Lond) 17 (1), 78-83. doi:10.7861/clinmedicine.17-1-78.

Shorey, Shefaly, Ng, Esperanza Debby, 2019. Evaluation of Mothers' Perceptions of a Technology-Based Supportive Educational Parenting Program (Part 2): Qualitative Study. J Med Internet Res 21 (2), e11065. doi:10.2196/11065.

Solhi, M., Abbasi, K., Azar, Ebadi Fard, Hosseini, A., 2019. Effect of Health Literacy Education on Self-Care in Pregnant Women: A Randomized Controlled Clinical Trial. Int J Community Based Nurs Midwifery 7 (1), 2-12.

Surita, F.G., Parpinelli, M.A., Yonehara, E., Krupa, F., Cecatti, J.G., 2007. Systemic lupus erythematosus and pregnancy: clinical evolution, maternal and perinatal outcomes and placental findings. Sao Paulo Med J 125 (2), 91-95. doi:10.1590 S1516-31802007000200005.

Tingström, J., Barimani, M., Sonesson, S.E., Wahren-Herlenius, M., Henriksson, E.W., 2010. The experiences of pregnancy in women with SSA/Ro52 autoantibodies. Musculoskeletal Care 8 (4), 215-223. doi:10.1002/msc.189.

Tong, A., Sainsbury, P., Craig, J., 2007. Consolidated criteria for reporting qualitative research (COREQ): a 32-item checklist for interviews and focus groups. Int J Qual Health Care 19 (6), 349-357. doi:10.1093/intahc/mzm042.

Turato, E.R., 2011. Treaty of Clinical Qualitative Research Methodology: Theoretical-Epistemological Comparative Discussion and Application in the Areas of Health and Human Sciences], 5th ed. Vozes: Petrópolis, Brazil.

Watson, B., Fuller-Tyszkiewicz, M., Broadbent, J., Skouteris, H., 2015. The meaning of body image experiences during the perinatal period: A systematic review of the qualitative literature. Body Image 14, 102-113. doi:10.1016/j.bodyim.2015.04. 005.

Watson, J., Simmonds, A., Fontaine, La, Fockler, M.E., 2019. Pregnancy and infant loss: a survey of families' experiences in Ontario Canada. BMC Pregnancy Childbirth 19 (1), 129. doi:10.1186/s12884-019-2270-2.

World, \& Organization, Health. (2018). Implementation guide for the medical eligibility criteria and selected practice recommendations for contraceptive use guidelines: a guide for integration of the World Health Organization (WHO) Medical eligibility criteria for contraceptive use (MEC) and Selected practice recommendations for contraceptive use (SPR) into national family planning guidelines. In. Geneva. 